\title{
A propósito de las ritidoplastias
}

\author{
Dr. Ricardo Baroudi \\ Cirujano Plástico \\ Editor de la Revista Brasileira de Cirurgia Plástica
}

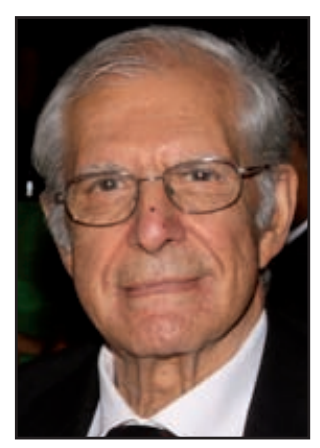

Baroudi, R.
Los mensajes de este comentario están dirigidos a los cirujanos plásticos que están en los primeros 10 años de actividad de la especialidad, especialmente los relativos a los criterios que utilizamos en nuestros pacientes de ambos sexos.

Las ritidoplastias, integradas actualmente en el arsenal terapéutico de la especialidad, tuvieron su inicio a finales del siglo XIX y en el inicio del siglo XX. Desde entonces hasta hoy hemos pasado por continuos refinamientos técnicos y tácticos para rejuvenecer los párpados, la cara y el cuello, logrando efectos naturales, como si las personas tuviesen 10 años menos de su edad biológica.

Como es de conocimiento de todos, las ritidoplastias pueden ser selectivas específicamente para el tercio superior de la cara, que comprende la frente con las cejas y el cuero cabelludo; para el tercio medio, hasta el borde de la mandíbula; y para el tercio inferior, con el cuello en toda su extensión. Igualmente, dentro de la rutina, estos tres tercios pueden operarse aisladamente o en conjunto, de acuerdo con la necesidad de cada paciente, de su sexo y del criterio del especialista. Las blefaroplastias a su vez, también pueden realizarse en el transcurso de una ritidoplastia o aisladamente.

En la evolución de la ritidoplastia, continuamente se han ido añadiendo procedimientos quirúrgicos, técnicas y tácticas invasivas o no con el objetivo de prolongar la eficacia de los resultados, cada una de ellas con sus ventajas y riesgos.

Fuera de estos aspectos, 9 factores propios de los pacientes determinan las limitaciones y posibilidades en relación al tiempo de eficacia de los resultados. Son los que siguen: década de la vida en que son operados, genética, hormonas, tabaquísmo, mayor o menor exposición al sol, variación de peso corporal después de la cirugía, calidad de la piel, si se trata de un caso primario, secundario o terciario... y, efectivamente, del factor número 9, la experiencia del cirujano.

Estos factores, combinados en diversos grados, están siempre conectados, haciendo posible o no evaluar y prometer un tiempo de eficacia, así como adelantar con un pequeño margen de error los efectos previsibles.

Cualquiera que sea la actividad médica, sabemos que se trata de una ciencia de verdades transitorias. Muchas técnicas han sido creadas, mejoradas, cambiadas y abandonadas. En este abanico de situaciones, la ritidoplastia tiene un pasado y continúa pasando por nuevas etapas. No vamos analizar lo que ha ocurrido con la ritidoplastia subperióstica, con el SMAS, con los implantes de hilos metálicos, con la incisión coronal, con las ritidoplastias endoscópicas, con las disecciones cutáneas extensas, etc. En todas ellas, los periodos de eficacia fueron diversos en función de los 9 factores señalados anteriormente. Todas tuvieron su ascensión, estabilización y caída.

Paralelamente, la Dermatología logró con el laser y demás tipos de tratamiento de la piel una llamativa mejora de su calidad, postergando la indicación de ritidoplastia a la última instancia, cuando los tratamientos no invasivos dejaban de ser eficaces. Por razones varias, la flacidez de la piel del cuello y de la cara, las arrugas profundas y el nivel de vanidad, son las razones más frecuentes para llegar a la ritidoplastia.

En las 2 últimas décadas se ha producido una clara ruptura de los límites entre la Cirugía Plástica y las especialidades afines. No necesitamos detallar. Basta observar a los oftalmólogos haciendo blefaroplastias y ritidoplastias, a los otorrinolaringólogos haciendo rinoplastias, a los ginecólogos y obstetras haciendo abdominoplastias y liposucciones, etc. Una verdadera carrera en el mercado con finalidades pecuniarias.

En realidad, al menos en Brasil, todo médico con su inscripción en el Consejo Médico del Departamento en que vive y practica su especialidad, está dentro de las reglas profesionales. Hasta el momento, todavía no están aclaradas formalmente bajo regulación las cirugías que formalmente deben ser hechas por los cirujanos plásticos. Hay que esperar que en un futuro breve, estos puntos aún no definidos sean regularizados. Mientras tanto, todos estaremos sujetos a juicios por mala práctica, incluso los cirujanos plásticos

Lo que está ocurriendo con las especialidades afines a la Cirugía Plástica era algo esperado. Cabe a los cirujanos plásticos, y eso está ocurriendo, lograr resultados mejores que los de aquellos que están fuera de nuestra especialidad en una competición de precios y de calidad de resultados; aquí se incluye la cosmiatría y el laser

Por encima de todos estos aspectos, no hay que olvidar también que hace 3 o más décadas, las ritidoplastias así como las demás cirugías estéticas eran como un secreto de estado, llevado con total sigilo por los pacientes. Lentamente pasaron a ser signo de status social, con comparación de resultados, precios, cicatrices, etc. En otras palabras, el cirujano plástico pasó a dejar su firma en sus cirugías, cualquiera que fuera la región del cuerpo intervenida.

En los Estados Unidos este proceso ocurrió también hace décadas, pero todavía se da, de tal forma que los cirujanos plásticos que inician sus actividades según una tendencia, deben continuarla. La era del cirujano plástico calificado que para todas las áreas de la especialidad entró en extinción. No hay necesidad de ejemplos. Todos ya los conocemos. De esta forma, aquellos calificados por sus buenos resultados, son fácilmente localizados a través de sus pacientes felices que los recomendarán a otros pacientes candidatos de su área de influencia. Como he dicho anteriormente, pasamos a dejar nuestra firma en las cirugías que realizamos.

Esto me ocurrió a mí en mis últimos 20 años de actividad en nuestra especialidad, de forma similar a como sucede en todos los países. En verdad, vendemos nuestra especialidad.

Importante también.... decir no a la operación de un paciente no nos hace ganar dinero, pero eleva nuestra dignidad y respeto profesional delante de aquellos que nos buscan profesionalmente y en el medio en que vivimos. 